\title{
CAPSULE COMMENTARIES \\ Capsule Commentary on Raghavan et al., Incident Type 2 Diabetes Risk is Influenced by Obesity and Diabetes in Social Contacts: A Social Network Analysis
}

\author{
Namratha R. Kandula, MD, MPH \\ Feinberg School of Medicine, Division of General Internal Medicine, Northwestern University, Chicago, IL, USA.
}

J Gen Intern Med 31(10): 1212

DOI: $10.1007 / \mathrm{s} 11606-016-3815-y$

(C) Society of General Internal Medicine 2016

$\mathrm{S}$ ocial relationships are established correlates of health behavior, physical and mental health, and mortality. ${ }^{1}$ In this issue of JGIM, Raghavan et al. report an association between having a social contact with diabetes or with obesity and incident type 2 diabetes mellitus during 37 years of follow-up of a subgroup from the Framingham Offspring Study. ${ }^{2}$ The study includes baseline and follow-up data from 4797 participants and 692 incident type 2 diabetes cases. A strength of this study is the ability to test the temporal association between the independent variable and the outcome variable at multiple times.

While studies have shown that obesity and type 2 diabetes clusters in social networks, ${ }^{3}$ the current study uses longitudinal data to delineate associations between specific types of social contacts and incident type 2 diabetes. The main finding was that incident diabetes in Framingham participants was associated with diabetes (but not obesity) in participants' siblings and obesity (but not diabetes) in participants' spouses. Their finding that the association differed depending on whether the social contact was a spouse or a sibling generates hypotheses about how behaviors may spread over time and influence type 2 diabetes risk. For example, a spouse may facilitate or inhibit daily health behaviors that influence diabetes risk, whereas siblings share genetic risk and early life exposures.

This study raises an important question, "Where do we begin to engage social relationships in type 2 diabetes prevention?" For clinicians, this study reaffirms the importance of asking patients about health risks of spouses, siblings and others who may be important. This information may help identify patients at particularly high risk and lead to discussions about who influences the patient's health behaviors. It remains unknown, however, if interventions that leverage social ties can improve health. ${ }^{4}$ Research is needed to identify the mechanistic links between social relationships and health outcomes and to answer key questions including: who in a person's social network is most influential for behavior change; how do contextual factors affect the influence of social relationships on health; and how is social influence transmitted? For now, social relationships remain an untapped resource for improving health.

Corresponding Author: Namratha R. Kandula, MD, MPH; Feinberg School of Medicine, Division of General Internal MedicineNorthwestern University, Chicago, IL, USA (e-mail: Namratha.Kandula@nm.org).

Compliance with ethical standards:

Conflicts of interest: The author has no conflicts of interest with this article.

\section{REFERENCES}

1. House JS, Landis KR, Umberson D. Social relationships and health. Science. 1988;241:540-545.

2. Raghavan S, Pachucki MC, Chang Y, Porneala B, Fox CS, Dupuis J, Meigs JB. Incident type 2 diabetes risk is influenced by obesity and diabetes in social contacts: a social network analysis. J Gen Intern Med. 2016. doi:10. 1007/s11606-016-3723-1.

3. Pancoska P, Buch S, Cecchetti A, Parmanto B, Vecchio M, Groark S, Paulsen S, Bardwell G, Morton C, Chester A, Branch R. Family networks of obesity and type 2 diabetes in rural appalachia. Clin Transl Sci. 2009;2:413-421.

4. Shaya FT, Chirikov VV, Howard D, Foster C, Costas J, Snitker S, Frimpter J, Kucharski K. Effect of social networks intervention in type 2 diabetes: a partial randomised study. J Epidemiol Community Health. 2014;68:326-332.

Published online July 29, 2016 